\section{Osteopontin expression and its relationship with prognostic factors in diffuse large B-cell lymphoma}

\author{
Gilberto Barranco, ${ }^{1}$ \\ Edith Fernández, ${ }^{2,3}$ Silvia Rivas, ${ }^{4}$ \\ Roxana Quezada, ${ }^{5}$ Dolores Nava, ${ }^{5}$ \\ José Aguilar, ${ }^{6}$ Abelardo García, ${ }^{2}$ \\ Horacio Astudillo, ${ }^{7}$ Carmen Lome, ${ }^{5}$ \\ Erika Ruiz ${ }^{2}$ \\ ${ }^{1}$ Department of Hematology, General \\ Hospital of Mexico, Mexico City; \\ ${ }^{2}$ Translational Medicine, National \\ Institute of Cancerology, Mexico City; \\ ${ }^{3}$ Computational Genomics, National \\ Institute of Genomic Medicine, Mexico \\ City; ${ }^{4}$ Department of Hematology, \\ National Institute of Cancerology, \\ Mexico City; ${ }^{5}$ Department of Pathology, \\ National Institute of Cancerology, \\ Mexico City; ${ }^{6}$ Department of Internal \\ Medicine, National Institute of \\ Cancerology, Mexico City; ${ }^{7}$ Laboratory \\ of Translational Cancer Research and \\ Cellular Therapy, National Medical \\ Center Siglo XXI, Mexico City, Mexico
}

\begin{abstract}
The aim of this study is to explore the expression of osteopontin (OPN) and its relationship with prognostic factors and survival in diffuse large $B$ cell lymphoma (DLBCL). A tissue microarray was performed for immunohistochemical evaluation. Contingency tables were analyzed for trends; chi-square test was used to determine differences between groups. Univariate and multivariate Cox proportional hazards-regression analyses were performed to evaluate the impact of prognostic factors on survival. Expression of OPN was observed in $28 \%$. It was different in non-germinal center DLBCL $(\mathrm{P}=0.04)$. type of cell, isoforms and receptors that recognize the proteins. ${ }^{8}$ In cancer, OPN induces the inhibition of apoptosis, favors tumor invasion, metastasis, angiogenesis and deregulation of cellular energetics, avoiding immune destruction and tumorpromoting inflammation. ${ }^{14}$

The increase in the production of osteopontin in different types of neoplasias has been associated with tumor aggressiveness and poor prognosis. ${ }^{13,15-22}$

A retrospect cohort study was conducted among patients with DLBCL; the purpose was to evaluate the expression of osteopontin in order to analyze its association with known prognostic factors and its influence on the overall survival.
\end{abstract} The mean overall survival (OS) was lower in patients with positive OPN expression (19.762; CI 95\% 14.269-25.255) it was not significant $(\mathrm{P}=0.123)$. It is not possible to establish a clear relationship between the expression by immunohistochemistry of osteopontin and a poor prognosis but it would be important to complement the analysis with other techniques as PCR or NGS that allow us to assess the influence of the isoforms and post-translational modifications of OPN on the biological behavior of DLBCL. Our findings indicate that OPN expression could be associated with a more aggressive variant of lymphoma: non-germinal center DLBCL.

\section{Introduction}

Diffuse large B cell lymphoma (DLBCL) is a heterogeneous disease which prognosis depends on clinical and biological factors. ${ }^{1}$ Advanced age, low performance status, advanced Ann Arbor stage, elevated lactate dehydrogenase (LDH) and extranodal disease have shown to be predictors of survival. ${ }^{2}$ The origin of the neoplastic cell (germinal center vs. non-germinal center), MYC, BCL6 and BCL2 translocations (double-hit or triple hit lymphoma) also influence the prognosis.

Osteopontin (OPN) is a non-collagenous extracellular matrix (ECM) protein with cytokine activity, expressed by various cell types, and is involved in multiple biological processes, both physiological and pathological; different isoforms $(a, b, c)$ can be produced by alternative splicing. ${ }^{3-7}$ The OPN was found intracellular and could also be secreted by an alternative translation mechanism and undergoes post-translational modifications (cleavage, glycosylation, etc.). ${ }^{8-11}$ OPN exerts its function binding to integrins and CD44. ${ }^{12,13}$ The biological function that OPN produces depend on the

\section{Materials and Methods}

\section{Patients and tissue specimens}

The present study was approved by the IRB Committee (Rev/93/16), Instituto Nacional de Cancerologia Mexico (INCan). Data were obtained from DLBCL database at INCan, between November 2014 and March 2016. All patients included in the
Correspondence: Erika Ruiz, San Fernando No.22. Col Belisario Dominguez Secc 16, Delegación Tlalpan, Ciudad de México C.P. 14080, México.

Tel.: +52.155.23441008

E-mail: betzabe100@yahoo.com.mx

Key words: osteopontin, lymphoma, prognosis.

Acknowledgments: we are grateful to Biologist Victor Hugo Olivera Rodríguez from Molecular Pathology and Immunohistochemistry Laboratory for her technical support in the construct of DLBCL tissue microarray.

To the Fundacion Carolina for the grant granted to GBL for the Pediatric Oncology and Adult Oncology research program BBVA.

Contributions: GB, SR, CL, RQ, and DN performed diagnosis and follow-up, analyzed data, and wrote the manuscript. EF and GB performed immunohistochemistry and wrote the manuscript. GB collected samples and clinical data. ER, JA, AG, HA designed the study, supervised research, and wrote the manuscript. All authors contributed to the preparation of the draft, and approved the final version for submission.

Conflict of interest: the authors declare no conflict of interest.

Funding: none.

Received for publication: 5 December 2018. Accepted for publication: 5 July 2019.

This work is licensed under a Creative Commons Attribution-NonCommercial 4.0 International License (CC BY-NC 4.0).

(C) Copyright: the Author(s), 2019

Licensee PAGEPress, Italy

Hematology Reports 2019; 11:7964

doi:10.4081/hr.2019.7964

analysis meet the following criteria: (i) histologically diagnosed as DLBL; (ii) tumor specimens with available quality for tissue microarray construction; (iii) complete data parameters to calculate the IPI and NCCNIPI scales on diagnosis (age, performance status, Ann Arbor stage, LDH levels and extranodal disease); (iv) Patients who were followed-up at the INCan. Clinical stage was determined according to the Ann Arbor staging system. Cellular origin was determined according to the Hans algorithm. ${ }^{23}$ As a result, 80 cases met the inclusion criteria and were incorporated in our study. The survival time was measured from the date of diagnosis to the date of death, or last follow-up. 


\section{Immunohistochemistry detection of osteopontin}

The paraffin-embedded primary tumor tissues of 80 patients were used to construct the DLBCL tissue microarray and were cut into $4 \mathrm{~mm}$ thick slices. For the IHC analysis, the slides were hydrated and antigenically reactivated using a citrate buffer $(0.01$ $\mathrm{M}$ citric acid, $0.01 \mathrm{M}$ sodium citrate) for 10 min at $90^{\circ} \mathrm{C}$. Endogenous peroxidase was blocked using Bloxall solution (Cat. SP6000. Vector), and after three washes with PBS $1 \mathrm{X}$, nonspecific antigenic sites were blocked using $1 \%$ bovine serum albumin (BSA)/Triton X-100 $0.1 \%$ dissolved PBS $1 \mathrm{X}$ during $30 \mathrm{~min}$ at $37^{\circ} \mathrm{C}$. Blocked solution was discarded and samples were incubated with OPN 1:200 (Cat. Sc-21742. Santa Cruz Biotechnology) dissolved in BSA $0.1 \%$ /Triton X-100 $0.01 \%$ overnight at $4^{\circ} \mathrm{C}$. The slides were washed 3 times with PBS $1 \mathrm{X}$, and the secondary antibody was used as specified by the manufacturer (mouse and rabbit specific HRP/AEC detection IHC kit, ab94705. Abcam). The slides were counterstained with Mayer's haematoxylin (Cat. HK100-9K. Bio Genex) and were mounted using Aqua Mounter Solution (Cat. BSB0091). Digital images of tissue sections $(40 \mathrm{X})$ were captured using a light microscope and a color AxioCam MRc5 camera (Zeiss).

Three different pathologists, blinded to the clinical information, determined the immunoreactivity of OPN. To evaluate the immunohistochemical expression of OPN, we used a score corresponding to the sum of both staining intensities $(0=$ negative; 1 =weak; 2 =intermediate; $3=$ strong) and the percentage of positive cells $(0=0 \%$ positive cells; $1=25 \%$ positive cells; $2=26-50 \%$ positive cells; $3>50 \%$ positive cells). The sum of $\mathrm{a}+\mathrm{b}$ reached a maximum score of 6 . A score equal or greater than 3 represented a positive immunohistochemical survey. ${ }^{24}$

\section{Statistical analysis}

The SPSS statistical software package version 20 was used for data analysis. Contingency tables were analyzed for trends; chi-square test was used to determine the significance of differences between groups for categorical variables. Univariate survival analysis was based on the Kaplan-Meier product limit estimator. Univariate and multivariate Cox proportional hazards-regression analyses were performed to evaluate the impact of prognostic factors on survival.

\section{Results}

\section{Patients}

In total, 48 females and 32 males were enrolled in our study, with a mean age of 59.64 years (range, $22-88$ years); $85 \%$ were treated with R-CHOP or CHOP-like chemotherapy. OPN was expressed in
$43.8 \%$ of the cases, primarily presenting a nuclear and cytoplasmic staining pattern, however when applying the score only $28 \%$ were considered positive; in some cases, OPN also presented little expression in macrophages and interstitial tissue (Figure $1)$.

\section{Correlation of OPN positivity with prognostic factors}

Positivity of OPN was not significantly correlated with age, performance status, Ann Arbor stage, LDH levels and extranodal disease but was significantly different in cases of non-germinal center lymphoma. Table 1 summarizes the detailed information of the included cases.

\section{Long-term survival}

The mean OS time for the entire cohort of patients was 24.04 months $(95 \%$ confidence interval [CI]: 21.4-26.6 months), with a 30 -months OS rate of $75.8 \%$; the median was not reached. Table 2 and Figure 2 summarize the survival details according to the expression of OPN.

\section{Factors that impact survival}

Univariate analysis, using the Cox proportional hazards regression model, demonstrated that performance status was the only factor that adversely affected OS (Table 3). Multivariate analysis did not identify any independent factor that adversely affected OS (Table 3).

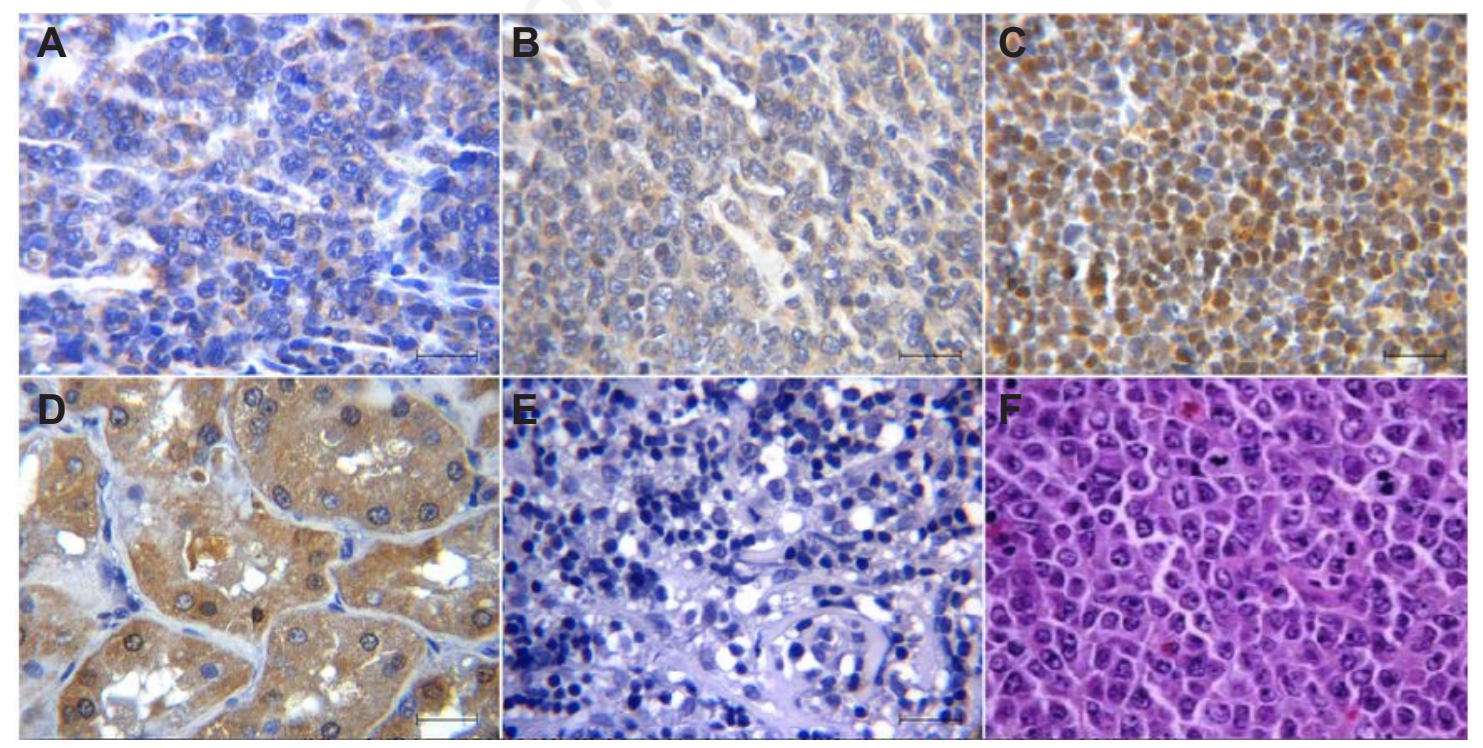

Figure 1. Osteopontin (OPN) expression immunohistochemistry in Diffuse Large B Cell Lymphoma (DLBCL). (A) Cytoplasmic OPN staining with positivity $<50 \%$. (B) Cytoplasmic OPN staining with positivity $>50 \%$. (C) Nuclear OPN staining. (D) Kidney sample was used as positive control of OPN. (E) Negative expression of OPN in DLBCL. (F) Hematoxylin and Eosin staining in a case of DLBCL. (A-F) Scale bar $=50 \mu \mathrm{m}$. Immunostaining in tissues was visualized at a magnification 400x. 


\section{Discussion and Conclusions}

DLBCL is an aggressive disease with a heterogeneous clinical behavior, while some patients may respond in a great way to treatment with immune-chemotherapy; however about $30 \%$ of cases do not achieve an adequate response. Although risk factors have been identified, it is important to identify targets that influence the prognosis and may be susceptible to treatment.

Osteopontin has been identified as a prognostic factor in hematologic and nonhematologic malignancies. Aggressive cases of DLBCL expressing osteopontin have been reported. ${ }^{25,26}$ In our study, we did not find a significant association between OPN expressions and known risk factors. But, we found a significant difference of OPN expression between germinal center and non-germinal center (NGC) lymphomas, that until today never has been reported, and this finding have clinical relevance since this last variant (NGC) is associated with a lower overall and progressionfree survival.

An association between the expression of osteopontin and extranodal disease has been also reported. ${ }^{27}$ OPN has been linked to the tropism of neoplastic B cells to the central nervous system (CNS) and it has been found that the OPN gene is up-regulated in the primary nervous system lymphoma. ${ }^{28-30}$ Although the characteristics of our study do not allow us to identify a relationship between OPN expression and CNS involvement by lymphoma, we consider that it is important to deepen the investigations to know if the expression of OPN in the neoplastic cell can predict an infiltration, posterior to the central nervous system, as it would help to discern which patients with DLBCL would benefit from prophylaxis to prevent CNS involvement.

In our study, a decreased overall survival was found in patients with positive OPN expression; however, this was not significant. In the multivariate analysis, all the risk factors evaluated (age, PS, Ann Arbor stage, elevated LDH, extranodal disease,

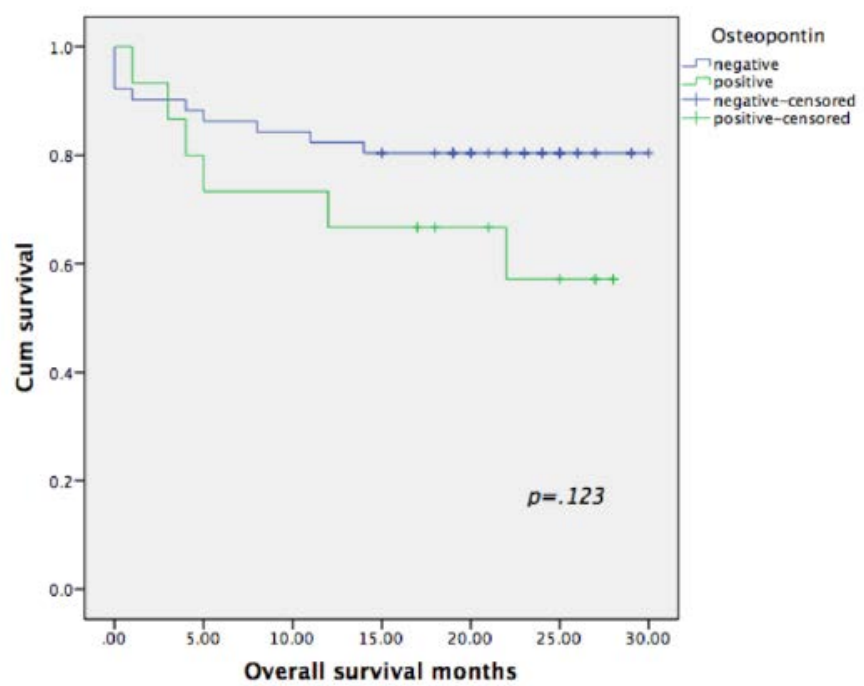

Figure 2. Survival curves of patients grouped according to the OPN expression.

Table 1. Correlation of osteopontin expression with clinical-pathological characteristics.

\begin{tabular}{|c|c|c|c|c|}
\hline Characteristics & Total (\%) & Positive (\%) & Negative (\%) & P-value \\
\hline $\begin{array}{l}\text { Age } \\
\quad<60 y \\
\quad>60 y\end{array}$ & $\begin{array}{l}35(43.8) \\
45(56.2)\end{array}$ & $\begin{array}{c}6(7.5) \\
14(17.5)\end{array}$ & $\begin{array}{l}29(36.3) \\
31(31.7)\end{array}$ & 0.152 \\
\hline $\begin{array}{c}\text { ECOG PS } \\
0,1 \\
>/=2\end{array}$ & $\begin{array}{l}57(71.3) \\
23(28.7) \\
\end{array}$ & $\begin{array}{l}12(15) \\
8(10)\end{array}$ & $\begin{array}{l}45(56.3) \\
15(18.7)\end{array}$ & 0.199 \\
\hline $\begin{array}{l}\text { Ann Arbor stage } \\
\text { I,II } \\
\text { III, IV }\end{array}$ & $\begin{array}{l}25(31.3) \\
55(68.7)\end{array}$ & $\begin{array}{c}8(10) \\
12(15)\end{array}$ & $\begin{array}{l}17(21.3) \\
43(53.7)\end{array}$ & 0.330 \\
\hline $\begin{array}{l}\text { LDH } \\
\quad \text { Normal } \\
\text { Increased } \\
\end{array}$ & $\begin{array}{l}31(38.7) \\
49(61.3)\end{array}$ & $\begin{array}{c}7(8.7) \\
13(16.3)\end{array}$ & $\begin{array}{l}24(30) \\
36(45)\end{array}$ & 0.691 \\
\hline $\begin{array}{l}\text { Extranodal disease } \\
\text { Negative } \\
\text { Positive }\end{array}$ & $\begin{array}{l}30(37.5) \\
50(62.5)\end{array}$ & $\begin{array}{c}6(7.5) \\
14(17.5)\end{array}$ & $\begin{array}{l}24(30) \\
36(45)\end{array}$ & 0.424 \\
\hline $\begin{array}{l}\text { Cell origin } \\
\quad \text { Germinal center } \\
\text { Non-germinal center } \\
\end{array}$ & $\begin{array}{l}42(59.2) \\
29(40.8)\end{array}$ & $\begin{array}{c}8(11.3) \\
12(16.9)\end{array}$ & $\begin{array}{l}34(47.9) \\
17(23.9)\end{array}$ & 0.040 \\
\hline
\end{tabular}

Table 2. Survival comparison between groups with positive and negative OPN expression.

\begin{tabular}{lccc} 
OPN & Mean $($ CI 95\%) & Median (CI 95\%) & P-value \\
Negative & $24.961(22.098-27.823)$ & Not reached & 0.123 \\
Positive & $19.762(14.269-25.255)$ & Not reached & \\
\hline
\end{tabular}

Table 3. Univariate and multivariate Cox regression analysis prognostic factors for OS.

\begin{tabular}{lccc} 
Variable & Univariate & & Multivariate \\
Age $>60 \mathrm{y}$ & $2.204(0.765-6.345)$ & P-value & Harard ratio (95\% IC) \\
ECOG $>$ /=2 & $3.739(1.385-10.096)$ & 0.143 & $3.275(0.906-11.840)$ \\
\hline Ann Arbor stage III, IV & $3.364(0.764-14.814)$ & 0.009 & $2.081(0.610-7.094)$ \\
LDH increased & $2.730(0.880-8.473)$ & 0.109 & $2.966(0.572-15.378)$ \\
\hline Extranodal disease & $2.338(0.753-7.255)$ & 0.082 & $1.763(0.465-6.677)$ \\
Non-germinal center & $1.307(0.458-3.727)$ & 0.142 & $1.449(0.422-4.969)$ \\
\hline Osteopontin expression & $2.161(0.785-5.952)$ & 0.617 & $1.277(0.370-4.408)$ \\
\hline
\end{tabular}


cell origin and OPN expression) confer an increased risk of mortality, but were not statistically significant, probably due to size of our cohort and the losses in the follow-up of the patients.

In other types of neoplasms, the identification of the different OPN isoforms has allowed to relate some of them to the prognosis, an example could be breast cancer, since the identification of the mRNA of the $\mathrm{C}$ isoform in tumor cells is associated to a poor prognosis, recurrence and decrease in disease-free survival, on the other hand, there is a decrease in the mRNA of isoform $\mathrm{A}$ as it increases the clinical stage by TMN; another example would be pancreatic cancer, since mRNA detection of isoform $\mathrm{C}$ is associated with metastatic disease while mRNA of isoform B is associated with decreased overall survival. ${ }^{18}$

In conclusion, the expression of osteopontin in DLBCL is relatively frequent, in our series it was observed in $28 \%$ of the cases, with a slight predominance in those cases of non-germinal center origin. Although it is not possible to establish a clear relationship between the expression by immunohistochemistry of osteopontin and a poor prognosis it would be important to complement the analysis with other techniques as PCR or NGS that allow us to assess the influence of the isoforms and post-translational modifications of OPN on the biological behavior of DLBCL.

\section{References}

1. Sehn LH, Gascoyne RD. Diffuse large B-cell lymphoma: optimizing outcome in the context of clinical and biologic heterogeneity. Blood 2015;125:22-32.

2. Zhou Z, Sehn LH, Rademaker AW, et al. An enhanced International Prognostic Index (NCCN-IPI) for patients with diffuse large B-cell lymphoma treated in the rituximab era. Blood 2015; 123:837-43

3. Kiefer MC, Bauer DM, Barr PJ. The cDNA and derived amino acid sequence for human osteopontin. Nucleic Acids Res 1989;17:3306.

4. Rangaswami H, Bulbule A, Kundu GC. Osteopontin: Role in cell signaling and cancer progression. Trends Cell Biol 2006;16:79-87.

5. Young MF, Kerr JM, Termine JD, et al. cDNA cloning, mRNA distribution and heterogeneity, chromosomal location, and RFLP analysis of human osteopontin (OPN). Genomics 1990;7:491-502.

6. Wang KX, Denhardt DT. Osteopontin:
Role in immune regulation and stress responses. Cytokine Growth Factor Rev 2008;19:333-45.

7. Kahles F, Findeisen HM, Bruemmer D. Osteopontin: A novel regulator at the cross roads of inflammation, obesity and diabetes. Mol Metab 2014;3:38493.

8. Gimba ER, Tilli TM. Human osteopontin splicing isoforms: Known roles, potential clinical applications and activated signaling pathways. Cancer Lett 2013;331:11-7.

9. Anborgh PH, Mutrie JC, Tuck AB, Chambers AF. Pre- and post-translational regulation of osteopontin in cancer. J Cell Commun Signal 2011;5:11122

10. Inoue M, Shinohara ML. Intracellular osteopontin (iOPN) and immunity. Immunol Res 2011;49:160-72.

11. Ahmed M, Behera R, Chakraborty G, et al. Osteopontin: a potentially important therapeutic target in cancer. Expert Opin Ther Target 2011;15:1113-26.

12. Lin J, Myers AL, Wang Z, et al. Osteopontin (OPN/SPP1) isoforms collectively enhance tumor cell invasion and dissemination in esophageal adenocarcinoma. Oncotarget 2015;6:2223957.

13. Chagan-Yasutan H, Tsukasaki K, Takahashi Y, et al. Involvement of osteopontin and its signaling molecule CD44 in clinicopathological features of adult $\mathrm{T}$ cell leukemia. Leuk Res 2011;35:1484-90.

14. Shevde LA, Samant RS. Role of osteopontin in the pathophysiology of cancer. Matrix Biol 2014;37:131-41.

15. Lee CY, Tien HF, Hou HA, et al. Marrow osteopontin level as a prognostic factor in acute myeloid leukaemia. Br J Haematol 2008;141:736-9.

16. Weber GF, Lett GS, Haubein NC. Osteopontin is a marker for cancer aggressiveness and patient survival. $\mathrm{Br}$ J Cancer 2010;103:861-9.

17. Minarik J, Pika T, Bacovsky J, et al. Prognostic Value of Hepatocyte Growth Factor, Syndecan-1, and Osteopontin in Multiple Myeloma and Monoclonal Gammopathy of Undetermined Significance. Sci World J 2012;2012: 356128.

18. Briones MA, Avendaño SE, Aparicio DI, et al. Osteopontin splice variants and polymorphisms in cancer progression and prognosis. Biochim Biophys 2017;1868:93-108.

19. Liersch R, Gerss J, Schliemann C, et al. Osteopontin is a prognostic factor for survival of acute myeloid leukemia patients. Blood 2012;119:5215-20.

20. Li Y, Sun B, Pei B, et al. OsteopontinExpressing Macrophages in Non-Small Cell Lung Cancer Predict Survival. Ann Thorac Surg 2015;99:1140-8.

21. Zhang T, Zhang D, Zhao D, et al. Osteopontin expression is associated with platinum-based chemotherapy response and prognosis of patients with advanced non small cell lung cancer. J Buon 2014;19:742-8.

22. Rodrigues LR, Teixeira J, Schmitt FL, et al. The role of osteopontin in tumor progression and metastasis in breast cancer. Cancer Epidemiol Biomarkers Prev 2007;16:1087-97.

23. Hans CP, Weisenburger DD, Greiner $\mathrm{TC}$, et al. Confirmation of the molecular classification of diffuse large B-cell lymphoma by immunohistochemistry using a tissue microarray. Neoplasia 2004;103:275-82.

24. Shijubu N, Uede T, Kon S, et al. Vascular Endothelial Growth Factor and Osteopontin in Stage I Lung Adenocarcinoma. Am J Respir Crit Care Med 1999;160:1269-73.

25. Starr JS, Jiang L, Li Z, et al. CD47 and osteopontin expression in diffuse large B-cell lymphoma with nodal and intravascular involvement. Clin Lymphoma Myeloma Leuk 2013;13: 597-601.

26. Jiang L, Marlow LA, Cooper SJ, et al. Selective central nervous system tropism of primary central nervous system lymphoma. Int J Clin Exp Pathol 2010; 3:763-7.

27. Pamuk GE, Uyanik MS, Pamuk ON, et al. Decreased dickkopf-1 levels in chronic lymphocytic leukemia and increased osteopontin levels in nonHodgkin's lymphoma at initial diagnosis: Could they be playing roles in pathogenesis? Hematology 2015;20: 267-71.

28. Yuan J, Gu K, He J, Sharma S. Preferential up-regulation of osteopontin in primary central nervous system lymphoma does not correlate with putative receptor $\mathrm{CD} 44 \mathrm{v} 6$ or $\mathrm{CD} 44 \mathrm{H}$ expression. Hum Pathol 2013;44:60611.

29. Yushi Q, Li Z, Von Roemeling CA, et al. Osteopontin is a multi-faceted protumorigenic driver for central nervous system lymphoma. Oncotarget 2016;7: 32156-71.

30. Strehlow F, Bauer S, Martus P, et al. Osteopontin in cerebrospinal fluid as diagnostic biomarker for central nervous system lymphoma. J Neurooncol 2016;129:165-71. 